\title{
Management of preweaned bull calves on dairy operations in the United States
}

\author{
C. B. Shivley, ${ }^{1}$ J. E. Lombard, ${ }^{1 *}$ N. J. Urie, ${ }^{1}$ D. M. Weary, ${ }^{2}$ and M. A. G. von Keyserlingk ${ }^{2}$ \\ ${ }^{1}$ USDA-Animal and Plant Health Inspection Service-Veterinary Services-Center for Epidemiology and Animal Health, \\ National Animal Health Monitoring System, Fort Collins, CO 80526 \\ ${ }^{2}$ Animal Welfare Program, Faculty of Land and Food Systems, University of British Columbia, Vancouver, British Columbia, V6T 1Z4, Canada
}

\section{ABSTRACT}

Many calves born on dairy farms are male, but little research to date has focused on the management of these calves. The objective of this study was to survey management practices of preweaned dairy bull calves and compare these practices with those used for heifer calves on the same operations. This study was conducted as part of the USDA National Animal Health Monitoring System Dairy 2014 study and included a sample of 42 operations from 10 states. On average, $2.4 \%$ of bull calves died before leaving the operation, with most operations selling bull calves before weaning $(97.6 \%)$. Bull calves left the operation at an average age of $7.6 \mathrm{~d}$ (median $=4 \mathrm{~d}$ ). Producers reported that $96.3 \%$ of bull calves received colostrum. Of bulls that were fed colostrum, the vast majority (95.4\%) were hand-fed; the remaining calves received colostrum via a combination of hand-feeding and suckling $(3.1 \%)$ or by suckling only $(1.5 \%)$. In contrast, all heifer calves on those operations were only hand-fed colostrum. On average, bull calves received $3.1 \mathrm{~L}$ of colostrum at their first feeding at $4.3 \mathrm{~h}$ after birth compared with $2.9 \mathrm{~L}$ at $2.9 \mathrm{~h}$ after birth for heifer calves. In the first $24 \mathrm{~h}$, bull and heifer calves received 4.8 and $5.5 \mathrm{~L}$ of colostrum, respectively. Only $21.4 \%$ of operations dehorned bull calves; in comparison, heifer calves were dehorned on $90.5 \%$ of operations. Few operations used analgesics or anesthetics when dehorning bull calves, whereas $28.9 \%$ of operations used anesthetics or analgesics when dehorning heifer calves. Overall, $27.8 \%$ of operations castrated bull calves. Of the operations that did castrate bulls, $70.0 \%$ used a band at an average age of $6.3 \mathrm{wk}$; the remaining $30 \%$ of operations used a knife at 14.7 wk of age on average. Few operations used analgesics or anesthetics when castrating. These results illustrate differences in the care of bull and heifer calves

Received May 22, 2018.

Accepted January 15, 2019.

*Corresponding author: Jason.E.Lombard@aphis.usda.gov and suggest the need to improve education regarding recommended colostrum feeding and pain management practices in all calves regardless of sex.

Key words: passive transfer, animal welfare, disbudding, pain mitigation

\section{INTRODUCTION}

The care and management of neonatal dairy heifer calves has received considerable attention over the past several decades, including proper colostrum management and pain mitigation for routine procedures such as dehorning (Godden and McGuirk, 2008). However, little work has focused on the care and management of dairy bull calves. Veal calves have been identified to be at high risk of disease when they arrive on the veal operation (Renaud et al., 2018a), but little information about the treatment of bull calves on the operation of birth is currently available.

Colostrum is required to provide calves with immunoglobulins for passive transfer of immunity as well as the first source of energy, protein, vitamins, minerals, fat, and fluid (Godden, 2008). The 4 most important factors related to colostrum management for adequate passive transfer are colostrum quality, quantity, timing of feeding, and cleanliness (McGuirk and Collins, 2004).

Dehorning is routinely performed on dairy calves. Regardless of the method, dehorning is a painful experience for calves (Stafford and Mellor, 2011), and dehorning when the horn buds are small combined with analgesics and anesthetics can help mitigate this pain (Graf and Senn, 1999; Grondahl-Nielsen et al., 1999; Stafford and Mellor, 2005a). Male calves are sometimes castrated, and analgesics and anesthetics have been shown to reduce pain-related behaviors (Stafford and Mellor, 2005b). The use of pain mitigation is thought to improve production; however, production parameters are often not precise enough to reflect the pain associated with castration (Stafford and Mellor, 2005b), resulting in little evidence that pain management improves production (Newton and O'Connor, 2013). 
Limited evidence demonstrated that pain mitigation (sodium salicylate) can alleviate the decrease in ADG associated with dehorning and castration (Baldridge et al., 2011).

This article focuses on 3 important welfare-related aspects of dairy bull calf management: (1) colostrum management, (2) dehorning and castration procedures, and (3) pain mitigation practices for painful procedures. Where applicable we compare findings with the management practices of dairy heifer calves on the same operations.

\section{MATERIALS AND METHODS}

The USDA National Animal Health Monitoring System (NAHMS) conducts national surveys to collect information on the health, management, and productivity of domestic livestock and poultry (USDA, 2016). In 2014, a nationwide study was conducted to collect information about the US dairy industry. This study included a series of questionnaires administered to dairy producers. The first questionnaire was administered by National Agricultural Statistics Service (NASS) enumerators (phase 1) who visited operations and conducted face-to-face interviews with dairy producers during January 2014 (NASS questionnaire). The NASS questionnaire included questions regarding preweaned heifer management, including colostrum practices.

A mixed (meaning both probability and nonprobability) sampling approach was used for this study. Operations that completed the NASS questionnaire were eligible to continue in the study and complete the USDA Veterinary Services (VS) questionnaire (phase 2 ). The VS questionnaire was conducted during onfarm visits by USDA VS and state animal health staff from March through July 2014. The VS questionnaire included questions regarding surgical procedures, including dehorning of heifer calves and castration of bull calves and pain mitigation practices. Of the 265 operations that completed the VS questionnaire, 99 agreed to participate in a longitudinal calf study (referred to as the calf component) that focused on the health and management of preweaned heifer calves. In addition, 5 operations that did not participate in the NASS or VS components were recruited to participate in the calf component based on lower than expected enrollment in the calf component of the study. The calf component occurred from March 2014 through September 2015. Forty-two of the operations that had agreed to participate in the calf component additionally agreed to participate in the bull calf questionnaire (available at https://www.aphis.usda.gov/animal_health/nahms/ dairy/downloads/dairy14ques/BullCalf.pdf; Figure 1). The bull calf questionnaire was a 9-question survey asking about the management of bull calves on the operation during 2013. The bull calf questionnaire was conducted during on-farm visits by USDA VS and state animal health staff from May 2015 through March 2016. Respondents on the farm varied and included the owner of the operation or employees, commonly the calf manager. Questions specifically asked about bull calf management, including the number of bull calves born on the operation, stillbirths, colostrum management, dehorning practices, and at what age the bull calves left the operation, if applicable.

Information on heifer calf management was obtained from the NASS and VS questionnaires for 37 of the 42 operations that completed the bull calf survey. The 5 operations recruited for the calf component and that completed the bull calf survey were not part of the original NAHMS Dairy 2014 study, and no data from the NASS or VS questionnaires were available for those operations. Data from the calf component were used to determine practices related to colostrum management and dehorning practices used on heifer calves on those 5 operations. These data were then used to compare with results from the bull calf survey. Information on castration was not available for the 5 operations that were recruited, and 1 additional operation did not answer the castration questions.

Data from the NASS questionnaires were entered and validated at the state or regional level by NASS using SAS (version 9.4; SAS Institute Inc., Cary, NC). The national data set was validated a second time by NAHMS staff. Data from the VS questionnaire, the calf component, and the bull calf survey were entered and validated by the NAHMS staff using SAS. The data sets from the NASS questionnaire, the VS questionnaire, the calf component, and the bull calf survey were merged. Descriptive data were analyzed using the FREQ and MEANS procedures of SAS for categorical and continuous variables, respectively. A chi-squared test was used to compare the frequency of respondents to the bull calf questionnaire and nonrespondents by region and herd size. Responses on the NASS and VS questionnaires related to heifer calf management were compared, using a nonprobability analysis, with responses on the bull calf survey for all operations that completed the bull calf survey. Paired $t$-tests were used to compare operation-level means between bull calves and heifer calves. T-tests were used to compare means between different operation categories. A 2-sided McNemar test was used to compare categorical variables. On the NASS questionnaire, stillbirths were reported for all calves (heifer calves and bull calves combined) rather than just heifer calves; therefore, comparisons could not be made between reported stillbirths for bull calves and heifer calves. 


\section{RESULTS}

\section{General Results}

The bull calf survey was completed by $42(40.4 \%)$ of the 104 operations that participated in the calf component. These 42 operations were located in 10 states
(CO, IA, MI, MN, NY, OH, PA, VT, WA, and WI; Table 1). No significant differences by region or herd size between the 42 responding operations and the 62 nonrespondent operations were detected (Table 1). Due to the small sample size, differences by region and herd size were not evaluated.

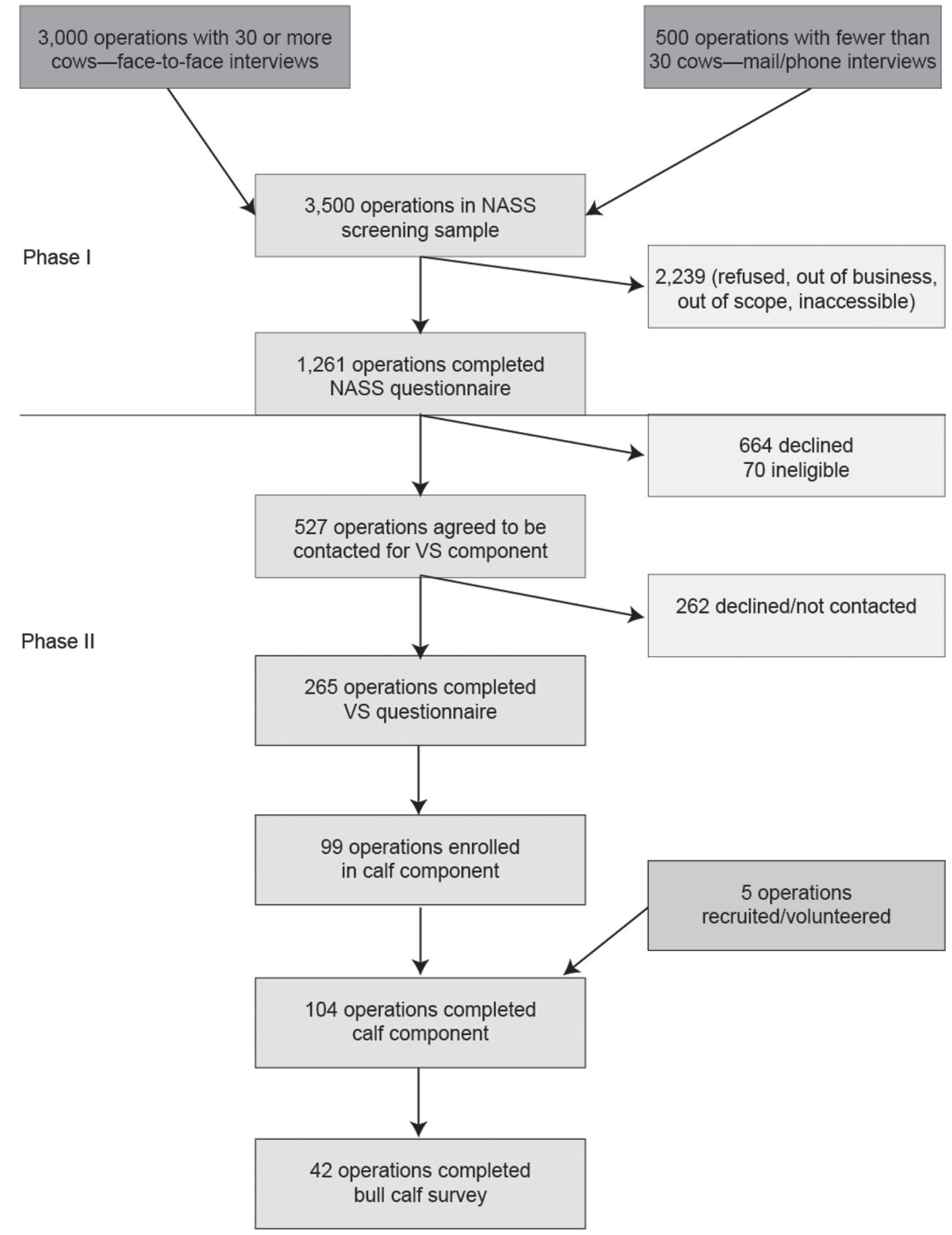

Figure 1. Flowchart for operation participation in the National Animal Health Monitoring System's Dairy 2014 bull calf survey. NASS = National Agricultural Statistics Service; VS = Veterinary Services. 
Table 1. Percentage and number of dairy operations ${ }^{1}(n=42)$ that completed the bull calf survey and percentage of nonrespondents $(\mathrm{n}=$ 62 ) by region and herd size

\begin{tabular}{lrrrr}
\hline & \multicolumn{3}{c}{ Operations } & \\
\cline { 2 - 3 } Item & $\%$ & No. & $\begin{array}{c}\text { Nonrespondents } \\
(\%)\end{array}$ & $P$-value \\
\hline Region & 19.0 & 8 & 29.0 & 0.25 \\
$\quad$ West & 81.0 & 34 & 71.0 & \\
$\quad$ East & & & & 0.67 \\
Herd size & 16.7 & 7 & 22.6 & \\
$\quad$ Small (30-99 cows) & 35.7 & 15 & 29.0 & \\
$\quad$ Medium (100-499 cows) & 47.6 & 20 & 48.4 & \\
$\quad$ Large (500+ cows) & & & \\
\hline
\end{tabular}

${ }^{1}$ Operations were a subset of the longitudinal heifer calf study, which was a component of the USDA National Animal Health Monitoring System Dairy 2014 study. States in the west included CO and WA, and states in the east included IA, MI, MN, NY, OH, PA, VT, and WI. Herd size was determined by the number of mature cows on the operation.

${ }^{2}$ Chi-squared test was used to compare respondents and nonrespondents by region and herd size.

Stillbirths, defined as calves born dead or that died within $48 \mathrm{~h}$ of birth, were higher for bull calves than all calves, with average stillbirth percentages of $7.4 \%$ (SD $=4.3)$ and $5.8 \%(\mathrm{SD}=3.9)$, respectively. The majority of operations $(97.6 \%)$ sold bull calves before weaning, at an average age of $7.6 \mathrm{~d}(\mathrm{SD}=11.8$; median $=4 \mathrm{~d})$, and $48.6 \%$ of operations sold bull calves through auctions. Overall, 2.4\% (SD: 3.0) of bull calves died before leaving the operation (excluding stillbirths). Mortality on operations where bull calves left the operation within $7 \mathrm{~d}$ was $1.6 \%(\mathrm{SD}=2.2)$, whereas mortality on operations where bull calves left after $7 \mathrm{~d}$ was higher at $4.9 \%(\mathrm{SD}=4.0 ; t=-2.35 ; \mathrm{df}=9.4$; Satterthwaite $P=0.04)$.

\section{Colostrum Management}

Operations reported that the majority of bull calves received colostrum $(96.3 \%$ of calves; $\mathrm{SD}=15.9)$ following birth (Table 2). However, of the bull calves that received colostrum, $1.5 \%(\mathrm{SD}=5.7)$ received colostrum by suckling the dam only, whereas no operations reported suckling as the sole means of providing colostrum to their heifer calves. Bull calves received colostrum at an average of $4.3 \mathrm{~h}(\mathrm{SD}=3.2)$ following birth compared with an average of $2.9 \mathrm{~h}(\mathrm{SD}=2.6)$ in heifer calves $(t=2.4 ; \mathrm{df}=39 ; P=0.020)$. The average volume of colostrum fed at the first feeding was not different for bull calves $(3.1 \mathrm{~L}, \mathrm{SD}=0.8)$ and heifer calves $(2.9 \mathrm{~L}, \mathrm{SD}=1.0 ; t=1.04 ; \mathrm{df}=40 ; P=0.303)$, but the volume fed in all subsequent feedings was less for bull calves $(1.7 \mathrm{~L}, \mathrm{SD}=1.5)$ than for heifer calves $(2.5 \mathrm{~L}, \mathrm{SD}=1.9 \mathrm{~L} ; t=-2.84 ; \mathrm{df}=40 ; P=0.007)$. A lower percentage of operations fed a second feeding of colostrum to bull calves compared with heifer calves (68.3 and $87.8 \%$, respectively; McNemar test: $P$ $=0.009)$. There was a trend for bull calves to be fed a lower total volume of colostrum within the first $24 \mathrm{~h}$ $(4.8 \mathrm{~L}, \mathrm{SD}=1.6)$ compared with heifer calves $(5.5 \mathrm{~L}$, $\mathrm{SD}=2.0 ; t=-1.91 ; \mathrm{df}=40 ; P=0.064)$.

\section{Dehorning Practices}

Of the 42 operations, $21.4 \%$ dehorned bull calves and $90.5 \%$ dehorned heifer calves (Table 3 ). A hot iron was the most commonly used method for both bull calves and heifer calves, used on 66.7 and $78.9 \%$ of operations that dehorned, respectively. Few operations reported using analgesics or anesthetics for hot iron dehorning on bull calves. However, $52.8 \%$ of bull calves dehorned using a hot iron received analgesics or anesthetics, illustrating that a few large operations with high numbers of bull calves can have a significant effect. For heifer calves, $30.0 \%$ of operations used analgesics or anesthetics for hot iron dehorning, and $29.6 \%$ of calves dehorned with that method received analgesics or anesthetics. For bull calves, 33.3\% of operations reported using other methods of dehorning (including caustic paste, tubes, spoons, gouges, saws, wires, or a Barnes

Table 2. Colostrum management practices for bull and heifer calves on the 42 participating dairy operations

\begin{tabular}{|c|c|c|c|c|c|c|c|c|c|}
\hline Item & \multicolumn{4}{|c|}{ Bull calves } & \multicolumn{4}{|c|}{ Heifer calves } & $P$-value \\
\hline Hand-feeding only (\%) & 95.4 & 11.6 & 80.0 & 100.0 & 88.9 & 30.2 & 40.0 & 100.0 & 0.097 \\
\hline Hand-feeding and suckling (\%) & 3.1 & 8.5 & 0.0 & 10.0 & 11.1 & 30.2 & 0.0 & 60.0 & 0.041 \\
\hline Suckling only (\%) & 1.5 & 5.7 & 0.0 & 0.0 & 0.0 & - & 0.0 & 0.0 & 0.089 \\
\hline Total colostrum in first $24 \mathrm{~h}^{1}(\mathrm{~L})$ & 4.8 & 1.6 & 2.8 & 6.6 & 5.5 & 2.0 & 3.8 & 7.6 & 0.064 \\
\hline
\end{tabular}

${ }^{1}$ For calves that were hand-fed colostrum. 
Table 3. Dehorning practices for bull and heifer calves on the 42 participating dairy operations

\begin{tabular}{|c|c|c|c|c|c|}
\hline Item & $\begin{array}{c}\text { Operations } \\
(\%)\end{array}$ & $\begin{array}{c}\text { Calves } \\
(\%)\end{array}$ & $\operatorname{Age}^{1}(\mathrm{~d})$ & $\begin{array}{l}\text { Operations using } \\
\text { analgesics or } \\
\text { anesthetics }(\%)\end{array}$ & $\begin{array}{l}\text { Dehorned calves } \\
\text { receiving analgesics } \\
\text { or anesthetics (\%) }\end{array}$ \\
\hline \multicolumn{6}{|l|}{ Bull calves } \\
\hline Dehorned & 21.4 & 20.2 & $15.1(14.8)$ & $-^{2}$ & 25.2 \\
\hline \multicolumn{6}{|l|}{ Method of dehorning } \\
\hline Hot iron & 66.7 & 47.7 & $19.8(15.4)$ & $-^{2}$ & 52.8 \\
\hline Other & 33.3 & 52.3 & $0.5(0.7)$ & 0.0 & 0.0 \\
\hline Total & 100.0 & 100.0 & & & \\
\hline \multicolumn{6}{|l|}{ Heifer calves } \\
\hline Dehorned & 90.5 & 78.2 & $8.5(7.7)$ & 28.9 & 19.6 \\
\hline \multicolumn{6}{|l|}{ Method of dehorning } \\
\hline Hot iron & 78.9 & 61.4 & $7.1(5.5)$ & 30.0 & 29.6 \\
\hline Other & 42.1 & 38.6 & $1.6(0.9)$ & 12.5 & 3.6 \\
\hline Total & 100.0 & 100.0 & & & \\
\hline
\end{tabular}

${ }^{1}$ Standard deviation in parentheses.

${ }^{2}$ Too few to report.

dehorner), whereas $42.1 \%$ of operations used other methods for heifer calves. The average age of dehorning bull calves was $15.1 \mathrm{~d}(\mathrm{SD}=14.8)$ compared with 8.5 $\mathrm{d}(\mathrm{SD}=7.7)$ for heifer calves.

\section{Castration Practices}

Of the 42 participating operations, 5 operations did not participate in either phase 1 or phase 2 (NASS and VS questionnaire administration), and 1 did not answer the castration questions in the bull calf survey. Of the remaining 36 operations, $27.8 \%$ of operations castrated bull calves; $20.4 \%$ of bull calves were castrated on the farm, and $8.3 \%$ of bull calves that were castrated received analgesics or anesthetics. Of the farms that castrated calves, $70.0 \%$ banded males at an average age of $6.3 \mathrm{wk}(\mathrm{SD}=2.3$; Table 4$)$. Few operations reported using analgesics or anesthetics. Surgical castration (e.g., knife) was used on $30.0 \%$ of operations when the calves were an average age of $14.7 \mathrm{wk}(\mathrm{SD}=8.3)$.

\section{DISCUSSION}

This study is one of the first to describe the management of colostrum administration and painful pro- cedures for bull calves on US dairy operations. Our results show differences in how bull and heifer calves were managed on the same operations. These results also show that many bull calves often undergo dehorning and castration without pain mitigation.

The percentage of stillbirths reported in bull calves was higher than the percentage of stillbirths in all calves on those operations. The national estimate for stillbirth percentage from the NAHMS Dairy 2014 study was $5.6 \%$, indicating that the subset of operations that completed the bull calf survey had a similar incidence of stillbirths in all calves compared with the national estimate (USDA, 2016). In the NASS questionnaire, this question was asked about all calves, not specifically heifer calves, so a direct comparison could not be made regarding stillbirths between bull calves and heifer calves. Previous research has shown that bull calves have higher rates of stillbirths than heifer calves (Meyer et al., 2001; Lombard et al., 2007), possibly due to higher rates of dystocia associated with the heavier BW of bull calves. Overall, an average of $2.4 \%$ of bull calves died before leaving the operation. For preweaned heifer calves in the NAHMS Dairy 2014 study, the mortality rate for preweaned heifers was $6.4 \%$ (USDA, 2016). The mortality rate for heifer calves accounts for

Table 4. Castration practices for the 36 participating dairy operations

\begin{tabular}{lccccc}
\hline Item & $\begin{array}{c}\text { Operations } \\
(\%)\end{array}$ & $\begin{array}{c}\text { Calves } \\
(\%)\end{array}$ & $\begin{array}{c}\text { Age } \\
(\mathrm{wk})\end{array}$ & $\begin{array}{c}\text { Operations using } \\
\text { analgesics or } \\
\text { anesthetics (\%) }\end{array}$ & $\begin{array}{c}\text { Castrated calves } \\
\text { receiving analgesics } \\
\text { or anesthetics (\%) }\end{array}$ \\
\hline $\begin{array}{l}\text { Castration } \\
\text { Method of castration }\end{array}$ & 27.8 & 20.4 & $8.8(5.9)$ & $-{ }^{2}$ & 8.3 \\
$\quad$ Band & 70.0 & 89.8 & $6.3(2.3)$ & $-^{2}$ & 9.2 \\
Knife & 30.0 & 10.2 & $14.7(8.3)$ & 0.0 & 0.0 \\
Total & 100.0 & 100.0 & & & \\
\hline
\end{tabular}

${ }^{1}$ Standard deviation in parentheses.

${ }^{2}$ Too few to report. 
the entire preweaning period, whereas most bull calves left the operation by $1 \mathrm{wk}$ of age, making it difficult to compare death rates by sex. In Canada, bull calves had a mortality rate of $2.8 \%$ within $21 \mathrm{~d}$ of arriving on the veal feeding operation (Renaud et al., 2018b).

The majority of operations sold their bull calves before weaning, with bull calves leaving the operation within about 1 wk after birth and approximately half of the operations selling the bull calves through auction. National estimates from the NAHMS Dairy 2014 study showed that $90.2 \%$ of operations sold bull and steer calves, with no differences across herd sizes, and almost two-thirds of operations $(61.8 \%)$ sold bull calves through auctions (USDA, 2016). Bull calves purchased from auctions have been shown to have a higher risk of mortality on veal operations (Pempek et al., 2017; Renaud et al., 2018a). Transportation early in life can lead to stress due to handling, particularly during loading and unloading, as well as thermal stress from adverse environmental conditions (Trunkfield and Broom, 1990; Stull and Reynolds, 2008). Transportation of calves can also lead to hunger and dehydration, putting calves at increased risk of mortality early in life (Renaud et al., 2018a). Calves are especially sensitive to cold temperatures during transport (Eicher, 2001). Recent work also shows that thermal stress impedes immunocompetence, particularly in young calves (Hulbert and Moisá, 2016). Gentle handling by trained drivers and handlers may help reduce the stress associated with transport (Stull and Reynolds, 2008; Grandin and Shivley, 2015). Bull calves in the United States are typically sold to beef feeders to be raised for beef, with a small number of bull calves sold for veal production (USDA, 2016). In some parts of the world veal calves are slaughtered at a very young age, making dehorning and castration unnecessary; however, this practice is not common in the United States. In the United States, the 28-h law is the only regulation regarding the transportation of animals, requiring that livestock transported across state lines be humanely unloaded into pens for food, water, and at least $5 \mathrm{~h}$ of rest every $28 \mathrm{~h}$ (US Government, 2009). However, several dairy programs include recommendations on the transport of bull calves, such as the Dairy Animal Care Quality Assurance program, which states that bull calves should not be marketed before $3 \mathrm{~d}$ of age and must be able to stand and walk before being transported (National Dairy Herd Information Association, 2017). The European Union has regulations on the transport of animals as well as guidelines on best practices for transporting animals, with specific guidance on the handling of young calves (Consortium of the Animal Transport Guides Project, 2017).

Although the majority of bull calves received colostrum, it is concerning that some calves did not. Given that calves are born agammaglobulinemic, providing adequate amounts of high-quality colostrum is critical for calves to resist infections in the first few weeks of life (Gulliksen et al., 2008). Suckling colostrum from the dam is concerning given that numerous factors can affect failure of passive transfer in suckling calves (e.g., time of separation for the dam, quality of colostrum, milk leakage before parturition; Weaver et al., 2000). Hand-feeding calves colostrum allows producers to closely monitor the timing, volume, and quality of the colostrum fed (Franklin et al., 2003).

The timing of colostrum feeding and the volume fed are critical components to ensure adequate passive transfer of immunity (Godden, 2008). In a study evaluating management factors associated with mortality in veal calves, failure of passive transfer was identified in $15 \%$ of male calves tested, with serum IgG levels below $10 \mathrm{~g} / \mathrm{L}$ (Renaud et al., 2018c). Although bull calves received their first feeding of colostrum within the recommended time frame, there was a large range of time of administration (90th percentile $=8 \mathrm{~h}$ ), putting some calves at risk of poor absorption of immunity due to delayed colostrum feeding. Although bull calves were fed similar amounts of colostrum at the first feeding as heifer calves, they were fed less in subsequent feedings such that the total volume of colostrum fed in the first $24 \mathrm{~h}$ after birth tended to be lower than that fed to the heifer calves. The total amount of colostrum fed to heifer calves in the first $24 \mathrm{~h}$ was comparable with that reported in an earlier study on heifer calves in Quebec (5.5 L; Vasseur et al., 2010). Calves should be fed at least $10 \%$ of BW of colostrum at the first feeding, which equates to about 4.0 L for the average Holstein heifer calf (Godden, 2008), and bull calves are generally heavier at birth. This standard was met on some but not all operations for bull calves or heifer calves; increasing the volume of colostrum fed at the first feeding is recommended.

That most participating operations did not dehorn bull calves may be due to the majority of bull calves leaving the operation within about 1 wk of age. Dehorning is important for bull calves that will be raised as beef because hide damage and carcass losses can be attributed to bruising from horns (Marshall, 1977). Most cattle will likely be dehorned eventually; however, disbudding and dehorning are both painful procedures (Stafford and Mellor, 2005a), and many countries now require pain mitigation when dehorning (Stock et al., 2013; Robbins et al., 2015). On the operations that dehorned bull calves, hot iron was the most commonly used method followed by other methods, likely due to the reliability of hot iron dehorning (AVMA, 2014b). Few operations reported using pain mitigation when dehorning bull calves. Overall, only $25.2 \%$ of bull calves 
that were dehorned received pain mitigation. The use of analgesics or anesthetics can reduce pain and distress for all dehorning methods (Graf and Senn, 1999; Stafford and Mellor, 2005a), yet this practice is still considered voluntary for most producers in the United States. Several programs now recommend the use of pain mitigation when dehorning, including the National Dairy FARM Program and one of the primary North American dairy processors (Saputo Inc., Montreal, QC, Canada); the programs do not differentiate between male and female calves (NMPF, 2016). The majority of those same operations dehorned heifer calves, but only $28.9 \%$ of operations that dehorned heifer calves used pain mitigation. National estimates from the NAHMS Dairy 2014 study showed that pain mitigation was used on $28.2 \%$ of the $94.3 \%$ of operations that dehorned heifer calves (USDA, 2016); in comparison, pain mitigation was used on only $17.7 \%$ of the $94.0 \%$ of operations that dehorned heifer calves in 2007 (USDA, 2009). Bull calves were dehorned at an older age than heifer calves on the same operation. The overall age at dehorning heifer calves from the NAHMS Dairy 2014 study was $9.2 \mathrm{~d}$ (USDA, 2018), similar to heifer calves on the operations in this study. The age at the time of disbudding or dehorning is considered a concern, with disbudding before the horn buds attach to the periosteum thought to result in fewer pain-related behaviors and faster healing (Stull and Reynolds, 2008; Stafford and Mellor, 2011). A survey of various stakeholders, including dairy producers and veterinarians, agreed that pain mitigation should be used for dehorning (Robbins et al., 2015). In addition to mitigating the pain associated with dehorning, Grondahl-Nielsen et al. (1999) reported that stockpersons performing the procedure commented on the fact that the use of analgesics reduced struggling by the calf. Clearly, regardless of sex of the calves, increased efforts must be targeted at understanding barriers to adoption of best practices for dehorning, including the use of pain mitigation protocols. In Brazil, the primary barrier to the adoption of pain mitigation was lack of knowledge of available techniques (Cardoso et al., 2016). Issues associated with dehorning can be eliminated by moving to polled cattle genetics; however, in the Dairy 2014 study, only $24.9 \%$ of US dairy operations reported using polled genetics (USDA, 2018).

Whereas most operations did not routinely castrate bull calves, of those that did castrate, the majority used the banding method and the remainder used surgical castration. Our results are similar to those reported in the NAHMS Dairy 2014 study, where the majority of the $35.5 \%$ of all operations that castrated bull calves used banding as the primary method (USDA, 2018). The public is concerned about the pain associated with castration (Weary et al., 2006), and numerous studies have evaluated different castration techniques and pain mitigation strategies. Although all methods cause acute pain, banding also causes long-lasting pain (Robertson et al., 1994; Molony et al., 1995), which is more difficult to manage. Pain associated with castration can decrease growth in cattle (Fisher, 1996). Pain mitigation can help alleviate the pain and distress associated with castration (Coetzee, 2011), and its use is supported by the American Veterinary Medical Association (AVMA, 2014a). Banding was the only castration technique where pain mitigation was used, yet most pain mitigation options currently available address only acute pain (Coetzee, 2011). Only $4.0 \%$ of operations in the NAHMS Dairy 2014 study reported using analgesics or anesthetics for castration, and also only for banding, which was used on $72.5 \%$ of operations that castrated male calves (USDA, 2018). We did not record the type of analgesic or anesthetic used for castration and were unable to evaluate pain management techniques. Regardless, pain relief should be used for any procedure that is known to cause pain (Stafford and Mellor, 2005b), and methods should be effective for controlling both intraoperative and postoperative pain.

There were limitations to this study. Data for this analysis came from several different components of the USDA NAHMS Dairy 2014 study, which were completed at different times and with different numbers of operations. Because the data collection occurred at different points in time, it was possible that different people on an operation completed each questionnaire. We are also aware that response bias may have affected the findings of our study. Two factors could have influenced the response bias. First, farms were visited across time, and because we did not control for respondent (individual who completed the questionnaires), there was a high chance that a different person filled out the survey at each visit. Second, in the case where the same person did answer the 2 questionnaires, there is a possibility that they simply provided the same type of responses for heifers and bulls despite in fact managing heifers and bulls differently. Because the bull calf survey was completed after the NASS and VS questionnaires, it is also possible that changes in management practices occurred on the operations between surveys. Only operations that participated in the calf component were eligible to complete the bull calf survey, limiting the eligible responses to 104 operations in our sample. Of those, only 42 completed the bull calf survey, with a potential for nonresponse bias. Data were self-reported by producers, with some responses relying on record keeping by the operation (e.g., number of bull calves born on the operation in 2014). Social desirability bias may have affected the results, with respondents potentially 
reporting what they believed to be the "right" response rather than actual on-farm practices. Although the overall number of completed bull calf surveys was lower than desired, the responses represented diversity in the dairy industry, including 10 states and operations of all sizes, with distributions across region and herd size classes not being significantly different between respondents and nonrespondents.

\section{CONCLUSIONS}

Bull calves were managed differently from heifer calves on the same operations regarding colostrum management and dehorning practices. Bull calves were fed colostrum later and at a lower volume after the first feeding compared with heifer calves. Most operations sold bull calves, and the calves left the operation within about $1 \mathrm{w}$ of age. The majority of operations did not dehorn or castrate bull calves before leaving, and when they did, pain management was rarely used. These results highlight the need for continued efforts to improve adoption of recommended colostrum feeding and pain management practices in bull and heifer calves.

\section{ACKNOWLEDGMENTS}

Data are from a dissertation submitted to Colorado State University by C. B. Shivley in partial fulfillment of requirements for the $\mathrm{PhD}$ degree. Portions of this article were presented at the 2016 American Dairy Science Association and American Society of Animal Science Joint Annual Meeting (Salt Lake City, UT). We thank the 42 dairy producers and their staff for participating in the study; the federal and state animal health personnel who assisted in collecting the data; Judy Rodriguez (USDA NAHMS, Fort Collins, CO) for technical assistance in data validation and analysis; and Temple Grandin (Colorado State University, Fort Collins) for assisting in funding C. B. Shivley during her $\mathrm{PhD}$ program.

\section{REFERENCES}

AVMA (American Veterinary Medical Association). 2014a. Welfare implications of castration of cattle. Accessed Apr. 14, 2016. https://www.avma.org/KB/Resources/LiteratureReviews/Pages/ castration-cattle-bgnd.aspx.

AVMA (American Veterinary Medical Association). 2014b. Welfare implications of dehorning and disbudding of cattle. Accessed Mar. 20 2018. https://www.avma.org/KB/Resources/LiteratureReviews/ Documents/dehorning_cattle_bgnd.pdf.

Baldridge, S. L., J. F. Coetzee, S. S. Dritz, J. B. Reinbold, R. Gehring, J. Havel, and B. Kukanich. 2011. Pharmacokinetics and physiologic effects of intramuscularly administered xylazine hydrochlorideketamine hydrochloride-butorphanol tartrate alone or in combination with orally administered sodium salicylate on biomarkers of pain in Holstein calves following castration and dehorning. Am. J. Vet. Res. 72:1305-1317.

Cardoso, C. S., M. A. G. von Keyserlingk, and M. J. Hötzel. 2016. Trading off animal welfare and production goals: Brazilian dairy farmers' perspectives on calf dehorning. Livest. Sci. 187:102-108.

Coetzee, J. F. 2011. A review of pain assessment techniques and pharmacological approaches to pain relief after bovine castration: Practical implications for cattle production within the United States. Appl. Anim. Behav. Sci. 135:192-213.

Consortium of the Animal Transport Guides Project. 2017. Guide to good practices for the transport of cattle. Accessed Mar. 21, 2018. http://animaltransportguides.eu/wp-content/uploads/2016/05/ Animal-Transport-Guides-Cattle-2017.pdf.

Eicher, S. D. 2001. Transportation of cattle in the dairy industry: Current research and future directions. J. Dairy Sci. 84:E19-E23.

Fisher, A. D. 1996. Effect of castration method and the provision of local anesthesia on plasma cortisol, scrotal circumference, growth, and feed intake of bull calves. J. Anim. Sci. 74:2336-2343.

Franklin, S. T., D. M. Amaral-Phillips, J. A. Jackson, and A. A. Campbell. 2003. Health and performance of Holstein calves that suckled or were hand-fed colostrum and were fed one of three physical forms of starter. J. Dairy Sci. 86:2145-2153.

Godden, S. 2008. Colostrum management for dairy calves. Vet. Clin. North Am. Food Anim. Pract. 24:19-39.

Godden, S., and S. McGuirk. 2008. Dairy heifer management. Vet. Clin. North Am. Food Anim. Pract. 24:1-210.

Graf, B., and M. Senn. 1999. Behavioural and physiological responses of calves to dehorning by heat cauterization with or without local anaesthesia. Appl. Anim. Behav. Sci. 62:153-171.

Grandin, T., and C. Shivley. 2015. How farm animals react and perceive stressful situations such as handling, restraint, and transport. Animals (Basel) 5:1233-1251.

Grondahl-Nielsen, C., H. B. Simonsen, J. D. Lund, and M. Hesselholt. 1999. Behavioural, endocrine and cardiac responses in young calves undergoing dehorning without and with use of sedation and analgesia. Vet. J. 158:14-20.

Gulliksen, S. M., K. I. Lie, L. Sølverød, and O. Østerås. 2008. Risk factors associated with colostrum quality in Norwegian dairy cows. J. Dairy Sci. 91:704-712.

Hulbert, L. E., and S. J. Moisá. 2016. Stress, immunity, and the management of calves. J. Dairy Sci. 99:3199-3216.

Lombard, J. E., F. B. Garry, S. M. Tomlinson, and L. P. Garber. 2007. Impacts of dystocia on health and survival of dairy calves. J. Dairy Sci. 90:1751-1760.

Marshall, B. L. 1977. Bruising in cattle presented for slaughter. N. Z. Vet. J. 25:83-86.

McGuirk, S. M., and M. Collins. 2004. Managing the production, storage, and delivery of colostrum. Vet. Clin. North Am. Food Anim. Pract. 20:593-603.

Meyer, C. L., P. J. Berger, K. J. Koehler, J. R. Thompson, and C. G. Sattler. 2001. Phenotypic trends in incidence of stillbirth for Holsteins in the United States. J. Dairy Sci. 84:515-523.

Molony, V., J. E. Kent, and I. S. Robertson. 1995. Assessment of acute and chronic pain after different methods of castration of calves. Appl. Anim. Behav. Sci. 46:33-48.

National Dairy Herd Information Association. 2017. Dairy animal care quality assurance. Accessed Mar. 21, 2018. https://www.bqa.org/ Media/BQA/Docs/dairybqamanual.pdf.

Newton, H. P., and A. M. O'Connor. 2013. The economics of pain management. Vet. Clin. North Am. Food Anim. Pract. 29:229-250.

NMPF (National Milk Producers Federation). 2016. Farmers Assuring Responsible Management (FARM) animal care reference manual. Accessed Mar. 20, 2018. https://nationaldairyfarm.com/wp -content/uploads/2018/10/Version-3-Manual-1.pdf.

Pempek, J., D. Trearchis, M. Masterson, G. Habing, and K. Proudfoot. 2017. Veal calf health on the day of arrival at growers in Ohio. J. Anim. Sci. 95:3863-3872.

Renaud, D. L., T. F. Duffield, S. J. LeBlanc, S. Ferguson, D. B. Haley, and D. F. Kelton. 2018a. Risk factors associated with mortality at a milk-fed veal calf facility: A prospective cohort study. J. Dairy Sci. 101:2659-2668. 
Renaud, D. L., T. F. Duffield, S. J. LeBlanc, D. B. Haley, and D. F. Kelton. 2018b. Clinical and metabolic indicators associated with early mortality at a milk-fed veal facility: A prospective case-control study. J. Dairy Sci. 101:2669-2678.

Renaud, D. L., D. F. Kelton, S. J. LeBlanc, D. B. Haley, and T. F. Duffield. 2018c. Calf management risk factors on dairy farms associated with male calf mortality on veal farms. J. Dairy Sci. 101:1785-1794.

Robbins, J., D. Weary, C. Schuppli, and M. Von Keyserlingk. 2015. Stakeholder views on treating pain due to dehorning dairy calves. Anim. Welf. 24:399-406.

Robertson, I. S., J. E. Kent, and V. Molony. 1994. Effect of different methods of castration on behaviour and plasma cortisol in calves of three ages. Res. Vet. Sci. 56:8-17.

Stafford, K. J., and D. Mellor. 2005a. Dehorning and disbudding distress and its alleviation in calves. Vet. J. 169:337-349.

Stafford, K. J., and D. Mellor. 2005b. The welfare significance of the castration of cattle: A review. N. Z. Vet. J. 53:271-278.

Stafford, K. J., and D. J. Mellor. 2011. Addressing the pain associated with disbudding and dehorning in cattle. Appl. Anim. Behav. Sci. $135: 226-231$.

Stock, M. L., S. L. Baldridge, D. Griffin, and J. F. Coetzee. 2013. Bovine dehorning: Assessing pain and providing analgesic management. Vet. Clin. North Am. Food Anim. Pract. 29:103-133.

Stull, C., and J. Reynolds. 2008. Calf welfare. Vet. Clin. North Am. Food Anim. Pract. 24:191-203.

Trunkfield, H. R., and D. M. Broom. 1990. The welfare of calves during handling and transport. Appl. Anim. Behav. Sci. 28:135-152.
US Government. 2009. 49 USC 80502: Transportation of animals (Twenty-eight hour law). Accessed Mar. 19, 2018. https://www .gpo.gov/fdsys/pkg/USCODE-2011-title49/pdf/USCODE-2011 -title49-subtitleX-chap805-sec80502.pdf.

USDA. 2009. Dairy 2007 part IV: Reference of dairy cattle health and management practices in the United States, 2007. Accessed Mar. 20, 2018. https://www.aphis.usda.gov/animal_health/nahms/ dairy/downloads/dairy07/Dairy07_dr_PartIV.pdf.

USDA. 2016. Dairy 2014 - Dairy cattle management practices in the United States, 2014. Accessed Aug. 4, 2017. https://www.aphis .usda.gov/animal_health/nahms/dairy/downloads/dairy14/ Dairy14_dr_PartI.pdf.

USDA. 2018. Dairy 2014-Health and management practices on U.S Dairy operations, 2014. Accessed Mar. 19, 2018. https://www .aphis.usda.gov/animal_health/nahms/dairy/downloads/dairy14/ Dairy14_dr_PartIII.pdf.

Vasseur, E., F. Borderas, R. I. Cue, D. Lefebvre, D. Pellerin, J. Rushen, K. M. Wade, and A. M. de Passillé. 2010. A survey of dairy calf management practices in Canada that affect animal welfare. J. Dairy Sci. 93:1307-1315.

Weary, D. M., L. Niel, F. C. Flower, and D. Fraser. 2006. Identifying and preventing pain in animals. Appl. Anim. Behav. Sci. 100:64-76.

Weaver, D. M., J. W. Tyler, D. C. VanMetre, D. E. Hostetler, and G. M. Barrington. 2000. Passive transfer of colostral immunoglobulins in calves. J. Vet. Intern. Med. 14:569-577. 